\title{
Breathing Patterns in Preterm and Term Infants Immediately After Birth
}

\author{
ARJAN B. TE PAS, CONNIE WONG, C. OMAR F. KAMLIN, JENNIFER A. DAWSON, COLIN J. MORLEY, AND PETER G. DAVIS
}

Division of Newborn Services, Royal Women's Hospital, Carlton, Victoria 3053, Australia

\begin{abstract}
There is limited data describing how preterm and term infants breathe spontaneously immediately after birth. We studied spontaneously breathing infants $\geq 29$ wk immediately after birth. Airway flow and tidal volume were measured for $90 \mathrm{~s}$ using a hot wire anemometer attached to a facemask. Twelve preterm and 13 term infants had recordings suitable for analysis. The median (interquartile range) proportion of expiratory braking was very high in both groups (preterm 90 [74-99] vs. term 87 [74-94]\%; NS). Crying pattern was the predominant breathing pattern for both groups (62 [36-77]\% vs. 64 [46-79]\%; NS). Preterm infants showed a higher incidence of expiratory hold pattern $(9[4-17] \%$ vs. $2[0-6] \% ; p=$ 0.02). Both groups had large tidal volumes (6.7 [3.9] vs. 6.5 [4.1] $\mathrm{mL} / \mathrm{kg}$ ), high peak inspiratory flows $(5.7[3.8] \mathrm{vs}$. $8.0[5] \mathrm{L} / \mathrm{min})$, lower peak expiratory flow (3.6 [2.4] vs. 4.8 [3.2] L/min), short inspiration time $(0.31[0.13]$ vs. $0.32[0.16] \mathrm{s})$ and long expiration time $(0.93[0.64] v s .1 .14[0.86] \mathrm{s})$. Directly after birth, both preterm and term infants frequently brake their expiration, mostly by crying. Preterm infants use significantly more expiratory breath holds to defend their lung volume. (Pediatr Res 65: 352-356, 2009)
\end{abstract}

$\mathrm{B}$ etween 1960 and 1986, observational data were gathered on breathing patterns immediately after birth from small numbers of term infants and were used to inform international guidelines for neonatal resuscitation (1-8). These studies demonstrated that the first breaths tend to be deeper and longer than subsequent breaths and are characterized by a short deep inspiration followed by a prolonged expiratory phase. This is known as expiratory braking and helps to develop and maintain functional residual capacity (FRC) during the immediate newborn period when the lung is partially liquid filled and the chest wall is very compliant $(9,10)$. Although this respiratory pattern has also been observed in preterm and term infants later in life (11-15), there are no data describing the breathing pattern of very preterm infants immediately after birth.

Antenatal glucocorticoid treatment has greatly improved postnatal lung function and many preterm infants breathe well and establish an FRC at birth by themselves or with only the support of continuous positive airway pressure (16-20). However, preterm infants have a poor respiratory drive, weak muscles, flexible ribs, surfactant deficiency, and impaired lung liquid clearance, which make it difficult for them to breathe easily at birth (21-24). With these inherent problems, we

Received May 6, 2008; accepted September 24, 2008

Correspondence: Arjan B. te Pas, M.D., Division of Newborn Services, Royal Women's Hospital Melbourne, 132 Grattan Street, Carlton, Victoria 3053, Australia; e-mail: arjan.tepas@ rwh.org.au

A.B.P. and J.A.D. are recipients of a Royal Women's Hospital postgraduate scholarship. hypothesized that preterm infants in the minutes after birth will show more expiratory braking than term infants.

The aim of this study was to compare the breathing patterns of preterm and term infants immediately after birth.

\section{METHODS}

All inborn infants, term and preterm $\geq 29$ wk gestation, who were expected to require no respiratory support at birth, were eligible for this study. The study was approved by the Royal Women's Hospital Research and Ethics committees. Written consent was obtained before birth.

Immediately after birth, as soon as the infant was placed on the resuscitation trolley, a facemask (Laerdal round mask, Laerdal Stavanger, Norway) was applied to the face, enclosing the mouth and nose. To ensure that there was no mask leak, a finger was applied around the infant's chin and held firmly during the recording. A hot wire anemometer (Florian: Acutronic Medical Systems AG, Zug, Switzerland) was attached proximally to the Laerdal mask measuring inspiratory and expiratory gas flow (see also Fig. 1) (25). The flow signal was integrated to provide inspired and expired tidal volume. The signals of airway flow and tidal volumes were digitized and recorded at $200 \mathrm{~Hz}$ using a neonatal respiratory physiologic recording program (Spectra, Grove Medical Limited, Hampton, UK).

To eliminate the risk of carbon dioxide retention caused by the mask (26), a bias flow of $2 \mathrm{~L} / \mathrm{min}$ of air was fed in through the face mask and the anemometer rezeroed (Fig. 1) (26). The dead space of the hot wire anemometers is $1 \mathrm{~mL}$ and clinically negligible (27).

To minimize interference with the normal monitoring and stabilization of preterm and term infants at birth, we recorded for only $90 \mathrm{~s}$. If there were signs of respiratory compromise, the study was abandoned and ventilatory support was given according to the Australian Neonatal Resuscitation guidelines (28).

Data collection. The following clinical data were collected: gestational age, birth weight, sex, mode of delivery, and Apgar score. The total number of breaths analyzed for each infant was noted, including their time after birth. Details of the waveforms of pressure, flow, and tidal volume were carefully analyzed to identify breathing patterns. Breaths of each pattern were analyzed in detail by a breath-to-breath analysis and the following parameters were calculated: respiratory rate, inspiration pattern and duration, expiratory hold (the time from zero flow at the end of inspiration to the start of the main expiratory flow), expiratory duration, postexpiratory pause (the time from zero flow at the end of expiration to the start of positive flow at the beginning of inspiration), duration of each breath, peak inspiratory flow, peak expiratory flow; inspiratory and expiratory tidal volumes (29).

Recordings were excluded if: a) there were signs of mask leak, b) the flow signal was disturbed by secretions or infant movements, $c$ ) there were signs of movement of the mask, or if ventilatory support was given.

Based on our earlier observations of spontaneous breathing patterns in infants at birth, we divided the breathing patterns by the type of expiration: braked or unbraked. These patterns were defined as follows.

Expiratory hold. Expiration is braked to a complete hold, postponing the main expiratory flow (Fig. 2) . This pattern is characterized by a period of no expiratory flow ending with a single expiratory flow peak or multiple expiratory flow peaks. Expiration is immediately followed by an inspiration, i.e., there is no postexpiratory pause.

Slow expiration. Expiration is characterized by an initial low expiratory flow rate ending with a single expiratory flow peak late in expiration and/or

Abbreviations: FRC, functional residual capacity 


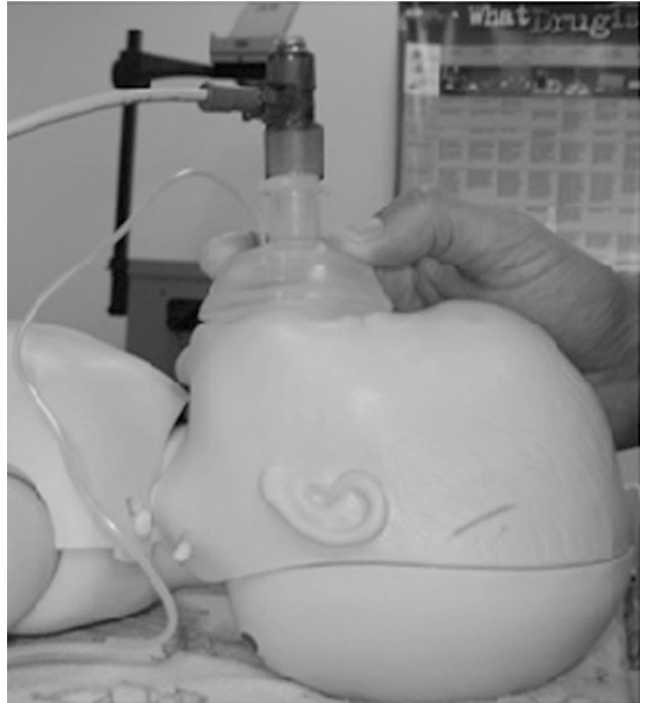

Figure 1. Placement of the open facemask demonstrated on a mannequin. The facemask was applied to the face, enclosing the mouth and nose. To ensure that there was no mask leak a finger was applied around the infant's chin was held firmly during the recording. A hot wire anemometer was attached proximally to the Laerdal mask. A bias flow of $2 \mathrm{~L} / \mathrm{min}$ of air was given through the facemask.

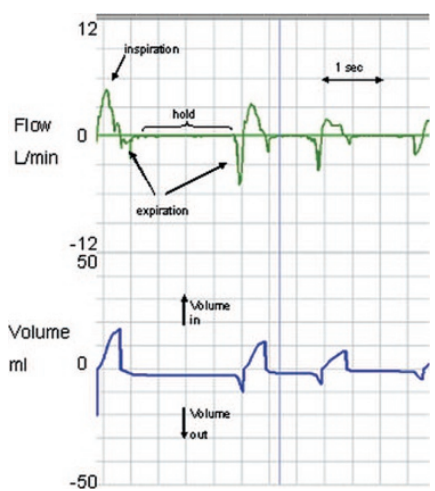

Figure 2. An example of three breaths showing an expiratory hold pattern in a spontaneously breathing infant of $31 \mathrm{wk}$. The pattern is characterized by a period of no expiratory flow ending with a single expiratory flow peak or multiple expiratory flow peaks. Expiration is immediately followed by an inspiration; there is no postexpiratory pause. Note in all figures that the software resets the volume trace at the end of inspiration and end of expiration as soon as the flow reaches baseline. In this example, more volume enters than leaves the lung, which implies an increase in functional residual capacity.

frequently interrupted expiratory flow waves (Fig. 3). These are immediately followed by an inspiration.

Crying. Expiration is slowed by crying (Fig. 4). This pattern is characterized by a large inspiration followed by high frequency interruptions to the expiratory flow wave, which can be seen in the wave as a noise signal. Expiration is then immediately followed by inspiration. A cry was differentiated from a grunt in the recording by the following: 1) during the recording session, we labeled the breath in the recording the moment a cry or a grunt was heard, 2) in general, the noise signal in the expiratory pattern of a cry has a larger amplitude and higher frequency than a grunt.

Grunting. Expiration is slowed by grunting (Fig. 5). This pattern is characterized by a large inspiration followed by high frequency interruptions to the expiratory flow wave, which can be seen in the wave as a noise signal. Expiration is then immediately followed by inspiration.

Unbraked expiration patterns. These are characterized by uninterrupted expiration with peak expiratory flow early in expiration. Expiration is not

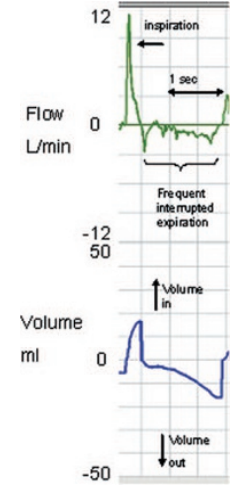

Figure 3. An example of a breath with a slow expiration pattern in an infant of $30 \mathrm{wk}$ gestation. In this pattern, expiratory flow is slowed or frequently interrupted. Expiration is immediately followed by an inspiration, i.e., there is no postexpiratory pause.

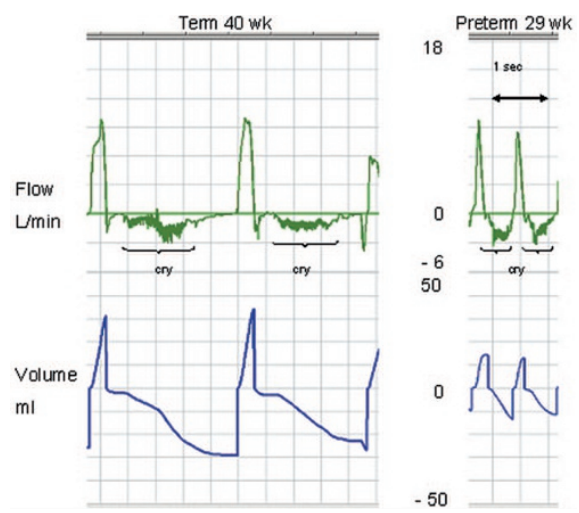

Figure 4. Examples of crying pattern in a term infant of $40 \mathrm{wk}$ gestation and a preterm infant of $29 \mathrm{wk}$ gestation. This pattern is characterized by a large inspiration followed by high frequency interruptions to the expiratory flow wave, which can be seen in the wave as a noise signal. Expiration is then immediately followed by inspiration. A cry has a higher amplitude and frequency than a grunt.

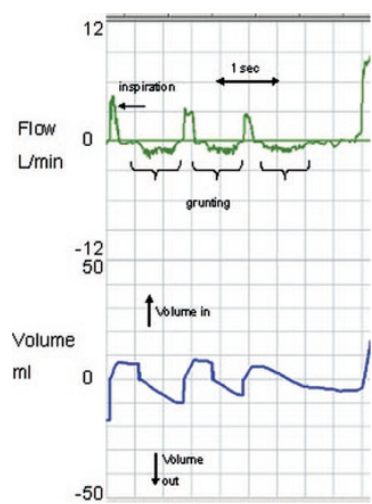

Figure 5. An example of expiration slowed by grunting in an infant of $33 \mathrm{wk}$ of gestation. This pattern is characterized by a large inspiration followed by high frequency interruptions to the expiratory flow wave, which can be seen in the wave as a noise signal. Expiration is then immediately followed by inspiration. In general, a grunt has lower amplitude and frequency than a cry.

prolonged (I:E time approximately 1:1.5) although sometimes the expiratory flow is followed by an expiratory pause before the next inspiration (Fig. 6).

The unbraked breathing pattern was called panting when the respiratory rate was greater than $60 / \mathrm{min}$. This is achieved by shortening the expiratory time (I:E time to approximately 1:1) and often small tidal volumes were noted. In these breaths, there was no postexpiratory pause before inspiration (Fig. 7). 


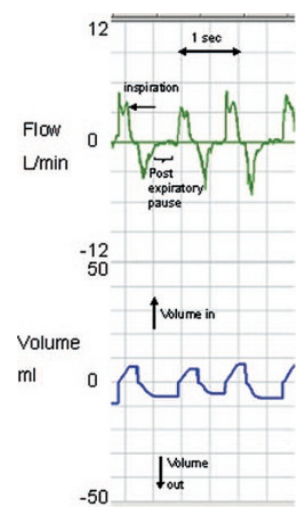

Figure 6. An example of a breath with a "normal" expiratory pattern without braking in an infant of $32 \mathrm{wk}$ gestation. This pattern is characterized by a peak expiratory flow at the beginning of expiration and sometimes showing a postexpiratory pause.

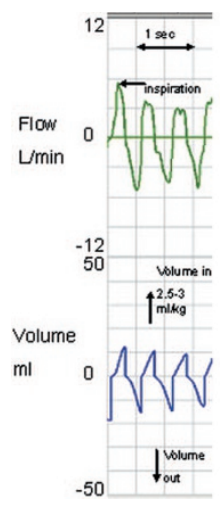

Figure 7. Example of panting pattern in a term infant. This pattern is characterized by a respiratory rate greater than $60 / \mathrm{min}$ (in this example $130 / \mathrm{min}$ ) by shortening the expiratory time (I:E time to approximately $1: 1$ ) and small tidal volumes are noted (in this example $2.5-3.0 \mathrm{~mL} / \mathrm{kg}$ ). In these breaths, there is no postexpiratory pause before inspiration.

Data analysis. Data are presented as numbers and proportions (\%) for categorical variables, and means with SD for normally distributed continuous variables and median (interquartile range) when the distribution was skewed. The $\chi^{2}$ test was used to detect differences between the two groups for categorical variables and student's $t$ test for continuous variables. Data were analyzed using SPSS software (SPSS for windows, version 15.0, 2006, Chicago, IL).

\section{RESULTS}

During the period August 2007-February 2008 there were 62 eligible infants. In seven infants, the mothers were not approached because the midwife/doctor considered it would be too stressful for the parents. In ten infants, the parents did not consent. In four infants, no recording was obtained due to technical problems. Forty-one recordings were made in 27 preterm infants and 14 term infants. Of these 16 recordings were excluded from analysis because secretions causing dirty flow signal in one term and one preterm infant and a further 14 preterm infants needed ventilatory support. Thus, there were 25 recordings available for analysis, 12 preterm and 13 term infants. We analyzed 769 breaths in the preterm infants and 749 breaths in the term infants. The characteristics of the infants studied are shown in Table 1.

Patterns of Breathing. The incidence of breaths of each pattern for both groups are shown in Table 2, and examples of each pattern are shown in Figures 2-7.
Table 1. Characteristics of the term and preterm infants

\begin{tabular}{lccc}
\hline \multicolumn{1}{c}{ Characteristics } & $\begin{array}{c}\text { Preterm } \\
(N=12)\end{array}$ & $\begin{array}{c}\text { Term } \\
(N=13)\end{array}$ & $\boldsymbol{p}$ \\
\hline Gestational age, wk, mean & $32(2.2)$ & $38.9(0.9)$ & $<0.001$ \\
$\quad$ (SD) & & & \\
Birth weight, g, mean (SD) & $2000(560)$ & $3340(530)$ & $<0.001$ \\
Apgar at 5 min, median (IQR) & $9(9-9)$ & $9(8-9)$ & NS \\
Time start recording, s, mean & $30(15)$ & $29(14)$ & NS \\
$\quad($ SD) & & & \\
Caesarean delivery (\%) & 33 & 54 & NS \\
\hline
\end{tabular}

Table 2. The proportion of breaths with different expiratory patterns for preterm and term infants

\begin{tabular}{lccc}
\hline & 12 Preterm & 13 Term & $p$ \\
\hline No. breaths & $58(45-82)$ & $62(34-73)$ & 0.5 \\
Braked expiration & & & \\
Prolonged & $12(3-17) \%$ & $11(3-18) \%$ & 0.9 \\
Hold & $9(4-17) \%$ & $2(0-6) \%$ & 0.02 \\
Grunt & $2(0-10) \%$ & $0(0-6) \%$ & 0.5 \\
Cry & $62(36-77) \%$ & $64(46-79) \%$ & 0.4 \\
Unbraked expiration & & & \\
Normal & $4(0-16) \%$ & $11(3-18) \%$ & 0.9 \\
Panting & $0(0-1) \%$ & $0(0-12) \%$ & 0.5 \\
\hline
\end{tabular}

The median (interquartile range) proportion of expiratory braking patterns was very high in both groups, in preterm infants $90(74-99) \%$ and in term infants $87(74-94) \%(p=$ $0.6)$. Of the braked patterns, expiratory hold pattern occurred more often in preterm infants $(9[4-17] \%$ vs. $2[0-6] \% ; p=$ $0.02)$. The most common breathing pattern for both groups was the crying pattern $(62[36-77] \%$ vs. $64[46-79] \% ; p=$ $0.4)$. The incidence of unbraked pattern was low in both groups $(10[3-27] \%$ vs. $13[6-25] \% ; p=0.6)$.

Respiratory Parameters. There was no difference in the average tidal volume measured between preterm and term infants $(6.7[3.9] v s .6 .5[4.1] \mathrm{mL} / \mathrm{kg} ; p=0.5)$. The breaths in both groups were characterized by a high peak flow during inspiration (5.7 [3.8] vs. $8.0[5] \mathrm{mL} / \mathrm{kg} ; p<0.001)$ and a lower peak flow during expiration (3.6 [2.4] vs. 4.8 [3.2] $\mathrm{mL} / \mathrm{kg} ; p<0.001)$. The average inspiration time was short and not different between the groups $(0.31[0.13]$ vs. 0.32 $[0.16] \mathrm{s} ; p=0.5)$. The average expiration time in both groups was long, but in preterm infants, it was shorter than in term infants $(0.93$ [0.64] vs. $1.14[0.86] \mathrm{s} ; p<0.001)$.

The values of the respiratory parameters of both groups when divided into breaths with braked and unbraked expiration are shown in Table 3. In both groups, breaths with braked expiration were characterized by larger tidal volume, larger peak inspiratory flow, longer expiration time, and smaller respiratory rate (see Table 3 ).

\section{DISCUSSION}

We have shown in this study that both term and preterm infants frequently brake their expiration in the first minutes of life. This is achieved most commonly by crying. The crying pattern has not been described in earlier reports $(7,30,31)$. All other interrupted expiratory patterns shown in this study were described previously and were considered strategies to defend 
Table 3. The respiratory parameters of the braked and unbraked breaths for both groups

\begin{tabular}{|c|c|c|c|c|c|c|}
\hline \multirow[b]{2}{*}{$\begin{array}{l}\text { Respiratory parameters, mean } \\
\text { (SD) }\end{array}$} & \multicolumn{3}{|c|}{ Braked expiration } & \multicolumn{3}{|c|}{ Unbraked expiration } \\
\hline & $\begin{array}{c}\text { Preterm } \\
(N=652 \text { breaths })\end{array}$ & $\begin{array}{c}\text { Term } \\
(N=598 \text { breaths })\end{array}$ & $p$ & $\begin{array}{c}\text { Preterm } \\
(N=117 \text { breaths })\end{array}$ & $\begin{array}{c}\text { Term } \\
(N=151 \text { breaths })\end{array}$ & $p$ \\
\hline Tidal volume (mL/kg) & $7.2(3.8)^{*}$ & $6.8(4.2)^{*}$ & NS & $3.7(2.2)^{*}$ & $5.5(3.4) *$ & $<0.001$ \\
\hline Inspiration time (s) & $0.32(0.14)$ & $0.33(0.16)$ & NS & $0.30(0.09)$ & $0.30(0.13)$ & NS \\
\hline Expiration time (s) & $1.03(0.84)^{*}$ & $1.33(1.02)^{*}$ & $<0.001$ & $0.41(0.16)^{*}$ & $0.43(0.26)^{*}$ & NS \\
\hline Peak flow inspiration (L/min) & $6.2(3.9)^{*}$ & $8.4(5.2)^{*}$ & $<0.001$ & $2.9(1.8)^{*}$ & $6.5(4.2)^{*}$ & $<0.001$ \\
\hline Peak flow expiration (L/min) & $-3.8(2.4)^{*}$ & $-4.3(2.8)^{*}$ & $<0.001$ & $-3.0(2.4)^{*}$ & $-6.3(4.0)^{*}$ & $<0.001$ \\
\hline Respiration rate $\left(\min ^{-1}\right)$ & $60(30)^{*}$ & $50(23)^{*}$ & $<0.001$ & $90(26)^{*}$ & $91(31)^{*}$ & NS \\
\hline
\end{tabular}

* Values of braked $v s$. unbraked pattern were significantly different in both groups $(p<0.001)$.

lung volume $(11,12,14,15,32-35)$. We were not able to show a difference in breathing between the groups, except that preterm infants use the expiratory breath hold more often than term infants.

This is the first study comparing the breathing patterns of term and preterm infants immediately after birth. Karlberg et al. (30) and Mortola et al. (7) reported the first few breaths in term infants and described similar interruptions in expiration with small or zero flow. These expiratory interruptions or braking were also observed in term infants at $10 \mathrm{~min}$ of life (11). They also occur in preterm and term infants later in life during active sleep $(15,33)$.

In newborns, with a very compliant chest wall, it is likely that expiratory braking mechanisms help maintain FRC. There are two mechanisms for stopping or slowing expiratory flow and maintaining an elevated lung volume during expiration. Diaphragmatic postinspiratory activity slows the rate of lung deflation by counteracting its passive recoil $(12,14,15,32,33)$. Closure or narrowing of the larynx increases the resistance to expiration $(11,15,34,35)$. During braked expiration, the closed or narrowed glottis, with increased intrapulmonary pressure from abdominal muscle contraction, causes the airway pressure to be maintained above atmospheric. This helps clear fluid from the lung, facilitate distribution of gas within the lung, and splint the alveoli and airways open $(3,4,7,8,11,30)$.

A cry at birth reassures clinicians that the infant is capable of taking a deep inspiration (36). The sound is produced during forced expiration by vibration of the vocal cords (37). In this study, we have shown that crying is a similar breathing pattern to grunting. It is an interruption of the expiratory flow with a higher frequency (Fig. 3) and amplitude than grunting. Grunting has been recognized as a dynamic braking of expiration by the larynx $(11,13)$, but crying has not been described earlier as a braking mechanism. The most likely reason for this is that in earlier studies breaths were excluded from analysis if the infant was crying $(7,11)$. Interestingly, Engstrom et al. recorded sound and intraesophageal pressure in the first minutes of life. Although they did not record flow and volume, they described breathing in the first minutes of life as a "crying period" characterized by deep breaths (31). It is likely that the prolonged high intrathoracic pressure on expiration during crying represents an important force for clearing fluid from the lung and facilitating lung aeration.

The tidal volumes in the nonbraked patterns are significantly lower in preterm infants compared with term infants. Preterm infants have difficulties aerating their lungs because of poor respiratory drive, weak muscles, flexible ribs, surfactant deficiency, and impaired lung liquid clearance $(21,22,24)$. We speculate that these factors become more obvious when breaths are not braked.

We observed an expiratory hold pattern more often in preterm infants. Preterm infants may have difficulty aerating their lungs and keeping them open and may need these expiratory hold maneuvers more often. It is possible that when these patterns are observed very frequently, it could indicate the infant may need respiratory support or, when already started, need to be optimized.

The braked pattern was characterized in both groups by a larger tidal volume. This probably reflects the large proportion of crying pattern that is accompanied by a large inspiration. The peak inspiratory flow we measured during the crying pattern in term infants is comparable to what has been measured in crying term infants later in life (36). However, we measured a much lower peak expiratory flow, which could indicate more braking occurred at birth than during crying later in life (36).

Making respiratory measurements immediately after birth is very difficult. This is an area of research where it is not possible to study large numbers in detail. We were only able to record more mature preterm infants because we aimed to record only those who were breathing without assistance. To have minimal interference with the monitoring and stabilization of preterm and term infants at delivery, we recorded for only $90 \mathrm{~s}$. It is possible that more differences between the groups would have appeared if more immature preterm infants were studied or if recordings were made for longer periods.

Although using a face mask with a pneumotachometer attached is an accepted and only method for measuring respiratory parameters after birth $(37,38)$, it may have influenced the breathing pattern by stimulating respiratory reflexes and thereby influencing the tidal volume and respiratory rate $(39,40)$. In previous studies, no adverse effects of using a face mask during the first breaths were reported $(1,2,7,11)$. In addition, an open face mask with a small pneumotachograph attached causes less interference to the infants' breathing than methods used in previous studies $(1-6,8)$.

In conclusion, this is the first report that describes in detail the breathing patterns of preterm and term infants immediately after birth. Both preterm and term infants frequent brake expiration, most often represented by a crying pattern. The crying pattern has not been described before but seems to be a method of breathing that uses expiratory braking and facil- 
itates lung volume recruitment. We have shown that preterm infants use significantly more expiratory breath holds to defend their lung volume.

\section{REFERENCES}

1. Karlberg P, Koch G 1962 Respiratory studies in newborn infants. III. Development of mechanics of breathing during the first week of life. A longitudinal study. Acta Paediatr Suppl 135:121-129

2. Karlberg P 1960 The adaptive changes in the immediate postnatal period, with particular reference to respiration. J Pediatr 56:585-604

3. Milner AD, Sauders RA 1977 Pressure and volume changes during the first breath of human neonates. Arch Dis Child 52:918-924

4. Vyas H, Milner AD, Hopkins IE 1981 Intrathoracic pressure and volume changes during the spontaneous onset of respiration in babies born by cesarean section and by vaginal delivery. J Pediatr 99:787-791

5. Vyas H, Milner AD, Hopkin IE, Falconer AD 1983 Role of labour in the establishment of functional residual capacity at birth. Arch Dis Child 58:512-517

6. Vyas H, Field D, Milner AD, Hopkin IE 1986 Determinants of the first inspiratory volume and functional residual capacity at birth. Pediatr Pulmonol 2:189-193

7. Mortola JP, Fisher JT, Smith JB, Fox GS, Weeks S, Willis D 1982 Onset of respiration in infants delivered by cesarean section. J Appl Physiol 52:716-724

8. Saunders RA, Milner AD 1978 Pulmonary pressure/volume relationships during the last phase of delivery and the first postnatal breaths in human subjects. J Pediatr 93:667-673

9. Mortola JP, Fisher JT, Smith B, Fox G, Weeks S 1982 Dynamics of breathing in infants. J Appl Physiol 52:1209-1215

10. Frappell PB, MacFarlane PM 2005 Development of mechanics and pulmonary reflexes. Respir Physiol Neurobiol 149:143-154

11. Fisher JT, Mortola JP, Smith JB, Fox GS, Weeks S 1982 Respiration in newborns: development of the control of breathing. Am Rev Respir Dis 125:650-657

12. Kosch PC, Stark AR 1984 Dynamic maintenance of end-expiratory lung volume in full-term infants. J Appl Physiol 57:1126-1133

13. Lindroth M, Johnson B, Ahlstrom H, Svenningsen NW 1981 Pulmonary mechanics in early infancy. Subclinical grunting in low-birth-weight infants. Pediatr Res 15:979-984

14. Mortola JP, Milic-Emili J, Noworaj A, Smith B, Fox G, Weeks S 1984 Muscle pressure and flow during expiration in infants. Am Rev Respir Dis 129:49-53

15. Radvanyi-Bouvet MF, Monset-Couchard M, Morel-Kahn F, Vicente G, DreyfusBrisac C 1982 Expiratory patterns during sleep in normal full-term and premature neonates. Biol Neonate 41:74-84

16. Bolt RJ, van Weissenbruch MM, Lafeber HN, Delemarre-van de Waal HA 2001 Glucocorticoids and lung development in the fetus and preterm infant. Pediatr Pulmonol 32:76-91

17. Jain L, Eaton DC 2006 Physiology of fetal lung fluid clearance and the effect of labor. Semin Perinatol 30:34-43

18. Aly H, Massaro AN, Patel K, El Mohandes AA 2005 Is it safer to intubate premature infants in the delivery room? Pediatrics 115:1660-1665

19. Thomson MA 2002 Continuous positive airway pressure and surfactant; combined data from animal experiments and clinical trials. Biol Neonate 81:16-19
20. Morley CJ, Davis PG, Doyle LW, Brion LP, Hascoet JM, Carlin JB 2008 Nasal CPAP or intubation at birth for very preterm infants. N Engl J Med 358:700-708

21. Gerhardt T, Bancalari E 1980 Chestwall compliance in full-term and premature infants. Acta Paediatr Scand 69:359-364

22. Heldt GP, McIlroy MB 1987 Dynamics of chest wall in preterm infants. J Appl Physiol 62:170-174

23. Barker PM, Gowen CW, Lawson EE, Knowles MR 1997 Decreased sodium ion absorption across nasal epithelium of very premature infants with respiratory distress syndrome. J Pediatr 130:373-377

24. Zelenina M, Zelenin S, Aperia A 2005 Water channels (aquaporins) and their role for postnatal adaptation. Pediatr Res 57:47R-53R

25. Plakk P, Liik P, Kingisepp PH 1998 Hot-wire anemometer for spirography. Med Biol Eng Comput 36:17-21

26. Marsh MJ, Ingram D, Milner AD 1993 The effect of instrumental dead space on measurement of breathing pattern and pulmonary mechanics in the newborn. Pediatr Pulmonol 16:316-322

27. Morris MG 1999 A simple new technique to measure the effective dead space of the face mask with a water volumeter in infants. Eur Respir J 14:1163-1166

28. Morley C 2007 New Australian Neonatal Resuscitation Guidelines. J Paediatr Child Health 43:6-8

29. Stick S 1996 Measurements during tidal breathing. In: Stocks J, Sly PD, Tepper RS, Morgan WJ (eds) Infant Respiratory Function Testing. John Wiley \& Sons Inc, New York, pp 118-119

30. Karlberg P, Cherry RB, Escardo FE, Koch G 1962 Pulmonary ventilation and mechanics of breathing in the first minutes of life, including the onset of respiration. Acta Paediatr 51:121-136

31. Engstrom L, Karlberg P, Rooth G, Tunell R 1966 The Onset of Respiration: A Study of Respiration and Changes in Blood Gases and Acid-base Balance. Association for the aid of crippled children, New York, pp 17-23

32. Lopes J, Muller NL, Bryan MH, Bryan AC 1981 Importance of inspiratory muscle tone in maintenance of FRC in the newborn. J Appl Physiol 51:830-834

33. Stark AR, Cohlan BA, Waggener TB, Frantz ID III, Kosch PC 1987 Regulation of end-expiratory lung volume during sleep in premature infants. J Appl Physiol 62:1117-1123

34. Milner AD, Saunders RA, Hopkin IE 1978 Is air trapping important in the maintenance of the functional residual capacity in the hours after birth? Early Hum Dev 2:97-105

35. Mortola JP, Magnante D, Saetta M 1985 Expiratory pattern of newborn mammals. J Appl Physiol 58:528-533

36. Long EC, Hull WE 1961 Respiratory volume-flow in the crying newborn infant. Pediatrics 27:373-377

37. Stocks J 1999 Lung function testing in infants. Pediatr Pulmonol Suppl 18:14-20

38. Schmalisch G, Foitzik B, Wauer RR, Stocks J 2001 Effect of apparatus dead space on breathing parameters in newborns: "flow-through" versus conventional techniques. Eur Respir J 17:108-114

39. Fleming PJ, Levine MR, Goncalves A 1982 Changes in respiratory pattern resulting from the use of a facemask to record respiration in newborn infants. Pediatr Res 16:1031-1034

40. Dolfin T, Duffty P, Wilkes D, England S, Bryan H 1983 Effects of a face mask and pneumotachograph on breathing in sleeping infants. Am Rev Respir Dis 128:977979 